\title{
The Advancing Internationalization of Our Research
}

Sigmar de Mello Rode Scientific Editor $\mathrm{n}$ order for a scientific journal to have visibility, it is essential that it be included in international databases that are well reputed by the academic world. These renowned databases, however, are quite selective, which means that their goal is not to include all that is published in the scientific world, but only the journals considered to have the best quality, based on the impact factors attributed to them. This criterion, whose validity may of course be questioned, can generally be considered a reflection of the scientific quality of a periodical.

Nevertheless, the specific goals of the databases also have to be considered, as well as the financial restraints to the indexation of journals, since the managing and text tagging jobs entailed in indexing periodicals are an expensive operation. Hence, it should be kept in mind that being indexed in a database merely means that the journal meets the goals and interests of the database and not necessarily that the journal is better than any other.

Inclusion in a database can occur in two different ways: either the periodical is invited to participate or it submits an application to do so.

The Brazilian Oral Research (BOR) journal was invited in October and November of this year to participate in the EBSCO Publishing, Index COPERNICUS, and GALE Cengage Learning international databases. In 1988, we were included in MEDLINE and, in the year 2000, we were invited to participate in Elsevier's well reputed SCOPUS database.

These participations further reinforce BOR's international visibility, and are important steps taken in our endeavor to internationalize our journal and, as a result, to internationalize Brazilian oral research.

We would also like to take a moment to congratulate Professor Carlos F. Santos, Editor of the Journal of Applied Oral Science, for the recent inclusion of his journal in the MEDLINE database, no doubt a great and well deserved achievement. 